\title{
PENGARUH RED FLAG DAN PELATIHAN TERHADAP KEMAMPUAN AUDITOR MENDETEKSI FRAUD DENGAN SKEPTISISME PROFESIONAL SEBAGAI VARIABEL INTERVENING
}

\author{
Aulia Dewi Gizta \\ Sekolah Tinggi Ilmu Ekonomi (STIE) \\ Pembangunan Tanjungpinang \\ auliadewigizta@yahoo.co.id
}

\begin{abstract}
Abstrak: Kemampuan auditor mendeteksi fraud merupakan kemampuan yang penting dimiliki oleh auditor, khususnya auditor internal karena merupakan auditor yang berada di dalam organisasi. Penelitian ini bertujuan untuk menguji pengaruh red flag dan pelatihan terhadap kemampuan auditor mendeteksi fraud dengan skeptisisme profesional sebagai variabel intervening. Populasi dari penelitian ini adalah seluruh auditor BPKP Perwakilan Provinsi Riau. Total responden berjumlah 58 orang auditor. Sampel ditentukan berdasarkan metode sensus, dimana semua anggota populasi digunakan sebagai sampel. Metode pengumpulan data dilakukan dengan metode survey melalui penyebaran kuesioner. Hasil penelitian ini menunjukkan bahwa redflag dan pelatihan berpengaruh signifikan terhadap skeptisisme profesional; redflag, pelatihan, skeptisisme profesional memiliki pengaruh langsung dan signifikan terhadap kemampuan auditor mendeteksi kecurangan; redflag dan pelatihan secara tidak langsung berpengaruh terhadap kemampuan auditor mendeteksi kecurangan memalui skeptisisme profesional.
\end{abstract}

Kata kunci: Red Flag, Pelatihan, Skeptisisme Profesional, dan Kemampuan Auditor Mendeteksi Kecurangan.

Abstract: The ability of auditors to detect fraud is an important capability possessed by auditors, especially internal auditors because they are auditors within the organization. The purpose of this study was to examine the effect of red flag and training on the auditor's ability to detect fraud by professional skepticism as intervening variable. The population of this study is auditor who work on Financial and Development Supervision Agency of Riau Province. The samples are determined based on sensus method, so that all the population used as a sample. Total respondents used in this research are 58 auditors. Data collection methods are carried out with survey method through questionnaire. The results of this study find that the red flag and training have significantly effect toward professional skepticism;; redflag, training, and professional skepticism have direct effect toward fraud detection ability of auditors; redflag and training have indirect effect toward fraud detection ability of auditors through professional skepticism.

Keywords: Red Flag, Training, Professional Skepticism, and Auditor's Ability to Detect Fraud. 


\section{PENDAHULUAN}

Kemampuan auditor mendeteksi kecurangan merupakan kemampuan yang penting dimiliki auditor untuk menemukan kecurangan. Terdapat tiga jenis kecurangan yaitu korupsi, penyalahgunaan aktiva, dan kecurangan laporan keuangan. Auditor yang memiliki ketelitian dalam bekerja, akurat dalam mengambil keputusan, dan mempunyai keinginan untuk melakukan pengembangan dalam mencari informasi dan bukti audit akan mampu untuk mendeteksi adanya kecurangan.

Kecurangan seperti korupsi dapat terjadi di sektor pemerintahan, untuk itu diperlukan pihak yang mampu mengawasi dan mendeteksi kecurangan. Di sektor pemerintahan, pihak pertama yang akan menemukan kecurangan disebut Aparat Pengawas Intern Pemerintah (APIP).

Tugas dari APIP terdapat pada PP Nomor 60 Tahun 2008 Pasal 48 ayat (2) yaitu APIP melakukan pengawasan intern melalui audit; reviu; evaluasi; pemantauan; dan kegiatan pengawasan lainnya. Standar audit APIP bagian perencanaan pasal 3022 menyatakan bahwa auditor harus merancang auditnya untuk mendeteksi adanya ketidakpatuhan terhadap peraturan perundang-undangan, kecurangan dan ketidakpatutan (abuse). Sebagai auditor internal pemerintah yang memiliki tugas mendeteksi kecurangan, APIP diharapkan mampu menjadi pihak pertama yang mendeteksi adanya kecurangan di pemerintahan.

Pasal 9 Undang-Undang Republik Indonesia
Nomor 15 Tahun 2004 menyatakan bahwa dalam menyelenggarakan pemeriksaan pengelolaan dan tanggung jawab keuangan negara, BPK dapat memanfaatkan hasil pemeriksaan APIP. Berdasarkan peraturan tersebut terlihat bahwa auditor internal seharusnya dapat menemukan fraud lebih dulu daripada auditor eksternal pemerintah (BPK) karena sifat pekerjaannya yang lebih dulu melakukan pengawasan intern. Namun kenyataannya, saat ini BPK lebih dulu menemukan fraud daripada APIP. (Indonesia Corruption Watch, 2018).

Pada tahun 2016, BPK menemukan penyimpangan sebesar $\mathrm{Rp}$ 3,5 miliar pada proyek sarana dan prasarana di Dispora Provinsi Riau (delikriau.com). Kejanggalan dalam proyek tersebut yaitu adanya kekurangan volume kerja dan kelebihan bayar (pekanbaru.tribunnews.com). Temuan auditor eksternal (BPK) terhadap penyimpangan tersebut menunjukkan adanya indikasi ketidakmampuan auditor internal dalam mendeteksi fraud. Karena semestinya auditor internal dapat melihat gejala kecurangan lebih dulu sebelum auditor eksternal.

Kemampuan auditor mendeteksi fraud dipengaruhi oleh beberapa faktor, seperti red flag dan pelatihan (Singleton, 2010; Drogalas, 2017). Auditor harus memiliki kemampuan mengenali red flag, seperti perubahan gaya hidup pegawai secara drastis maupun keengganan pegawai mengambil jatah cuti dari organisasi. Jika auditor mampu melihat adanya red flag, tentunya akan mempermudah auditor 
dalam mendeteksi kecurangan. Red flag selanjutnya juga dapat meningkatkan skeptisisme profesional auditor. Skeptisme profesional adalah sikap yang penuh dengan keingintahuan serta penilaian kritis atas bukti audit (Arens, 2008:186).

Penelitian mengenai efektivitas red flags dalam audit laporan keuangan pernah dilakukan oleh YÜCEL (2013), yang menemukan terdapat sekitar $20 \%$ auditor dalam penelitiannya yang sering memanfaatkan red flags untuk mendeteksi kecurangan.

Faktor selanjutnya yang dapat mempengaruhi kemampuan auditor mendeteksi fraud adalah pelatihan. Menurut Drogalas (2017), pelatihan mengenai kecurangan menggunakan simulasi kasus kecurangan yang dapat membantu auditor internal meningkatkan kinerja dan meningkatkan kemampuan untuk mendeteksi bukti kecurangan. Fraud audit training selanjutnya juga dapat meningkatkan skeptisisme profesional auditor. Karena,auditor yang pada awal memiliki skeptisisme yang rendah, setelah diberikan pelatihan menunjukkan peningkatan pada beberapa karakteristik skeptisisme (Fullerton dan Durstchi, 2004).

Menurut Putri (2017), Fraud audit training yang diukur dengan jumlah jam pelatihan auditor berpengaruh terhadap kemampuan pendeteksian kecurangan. Diharapkan dengan adanya pelatihan, dapat meningkatkan kemampuan auditor mendeteksi fraud.

Variabel intervening dalam penelitian ini adalah skeptisisme profesional. Auditor harus memiliki pikiran yang kritis dalam menilai tanggapan dari manajemen dan bukti untuk menentukan risiko adanya salah saji palsu (ACFE, 2003). Carpenter, Durtschi dan Gaynor (2002) dalam Nasution dan Fitriany (2012) mengungkapkan bahwa jika auditor lebih skeptis, mereka akan mampu lebih menaksir keberadaan kecurangan pada tahap perencanaan audit, yang akhirnya akan mengarahkan auditor untuk meningkatkan pendeteksian kecurangan pada tahap-tahap audit berikutnya.

Skeptisisme profesional dijadikan variabel intervening pada penelitian ini karena terdapat beberapa penelitian yang menunjukkan variabel independen tidak berpengaruh terhadap variabel dependen. Untuk itulah peneliti ingin menguji skeptisisme profesional sebagai variabel intervening dengan asumsi skeptisisme profesional dapat menjadi intervening hubungan antara variabel independen dengan variabel dependen.

Berdasarkan uraian latar belakang penelitian diatas, maka dapat dirumuskan beberapa permasalahan yang akan diteliti diantaranya :

1. Apakah red flag berpengaruh terhadap kemampuan auditor mendeteksi kecurangan (fraud)?

2. Apakah pelatihan berpengaruh terhadap kemampuan auditor mendeteksi kecurangan (fraud)?

3. Apakah skeptisisme profesional berpengaruh terhadap kemampuan auditor mendeteksi kecurangan (fraud)?

4. Apakah red flag berpengaruh terhadap 
skeptisisme profesional?

5. Apakah pelatihan berpengaruh terhadap skeptisisme profesional?

6. Apakah red flag berpengaruh terhadap kemampuan auditor mendeteksi kecurangan (fraud) melalui skeptisisme profesional?

7. Apakah pelatihan berpengaruh terhadap kemampuan auditor mendeteksi kecurangan (fraud) melalui skeptisisme profesional?

Dalam melakukan penelitian ini, penulis bertujuan ingin :

1. Untuk menguji dan menjelaskan pengaruh red flag, pelatihan dan skeptisisme profesional terhadap kemampuan auditor mendeteksi kecurangan (fraud).

2. Untuk menguji dan menjelaskan pengaruh red flag dan pelatihan terhadap skeptisisme profesional.

3. Untuk menguji dan menjelaskan pengaruh red flag dan pelatihan terhadap kemampuan auditor mendeteksi kecurangan (fraud) melalui skeptisisme profesional.

Penelitian ini memliki kegunaan sebagai berikut :

1. Bagi Auditor, informasi penelitian ini dapat digunakan sebagai motivasi untuk senantiasa memiliki pemahaman akan red flag, mengikuti pelatihan, dan menerapkan sikap skeptisisme profesional.

2. Bagi Akademisi dan Peneliti, penelitian ini dapat memberikan informasi kepada pihak-pihak terkait yang memerlukan hasil penelitian ini, juga menambah wawasan dan pengetahuan mengenai pengaruh red flag dan pelatihan terhadap kemampuan auditor dalam mendeteksi fraud melalui skeptisisme profesional.

3. Bagi Regulator, penelitian ini dapat memberikan masukan dalam membuat kebijakan untuk meningkatkan skeptisisme profesional dan kemampuan mendeteksi fraud bagi para auditor.

\section{TINJAUAN PUSTAKA}

Fraud pentagon theory menggambarkan faktor-faktor yang menyebabkan terjadinya kecurangan. Fraud pentagon theory merupakan pengembangan dari fraud triangle theory oleh Cressey (1953).Marks (2012) mengatakan bahwa terdapat 5 elemen pada teori fraud pentagonyaitu:1). Arogansi 2). Kompetensi 3). Peluang 4). Tekanan 5). Rasionalisasi.

Disonansi kognitif mempunyai arti keadaan psikologis yang tidak menyenangkan yang timbul ketika dalam diri manusia terjadi konflik antara dua kognisi atau konflik antara perilaku dan sikap (Noviyanti, 2008).Disonansi kognitif terjadi apabila auditor mempunyai kepercayaan tinggi terhadap klien, sehingga menyebabkan sikap skeptisme profesionalnya berada pada tingkat rendah, padahal standar profesional akuntan publik dan pemberian penaksiran risiko kecurangan yang tinggi dari atasan auditor menghendaki agar auditor bersikap skeptis.

Kemampuan auditor mendeteksi kecurangan adalah kemampuan yang dimiliki auditor untuk 
mengembangkan pencarian informasi ketika menemukan gejala yang dapat mengakibatkan kerugian bagi orang lain.

DiNapoli (2008) menekankan red flag sebagai keadaan yang berbeda dari aktivitas normal. Berbeda dengan Moeller (2009) yang menekankan red flag sebagai pertanda sesuatu yang tidak benar. Menurut Singleton (2010), red flag sangat penting untuk keberhasilan mendeteksi dan mencegah kecurangan. Red flag mengarah pada metode dan proses pendeteksian yang efektif. Fraud audit training adalah salah satu pelatihan agar mampu menginvestigasi dan mendeteksi kecurangan dalam laporan keuangan perusahaan (Pramudyastuti, 2014). Auditor dengan fraud training mengidentifikasi secara signifikan lebih banyak red flag dan memperoleh pengetahuan yang lebih besar tentang risiko kecurangan daripada auditor yang tidak menerima pelatihan.

Hipotesis dalam penelitian ini adalah sebagai berikut :

$\mathrm{H}_{1}$ : Red flag berpengaruh terhadap Kemampuan Auditor Mendeteksi Fraud

$\mathrm{H}_{2}$ : Pelatihan berpengaruh terhadap Kemampuan Auditor Mendeteksi Fraud

$\mathrm{H}_{3}$ : Red Flag berpengaruh terhadap Skeptisisme Profesional

$\mathrm{H}_{4}$ : Pelatihan berpengaruh terhadap Skeptisisme Profesional

$\mathrm{H}_{5}$ : Skeptisisme Profesional berpengaruh terhadap Kemampuan Auditor Mendeteksi Fraud
$\mathrm{H}_{6}$ : Red Flag berpengaruh terhadap Kemampuan Auditor Mendeteksi Fraud melalui Skeptisisme Profesional

$\mathrm{H}_{7}$ : Pelatihan berpengaruh terhadap Kemampuan Auditor Mendeteksi Fraud melalui Skeptisisme Profesional

\section{METODE PENELITIAN}

Populasi dalam penelitian ini adalah seluruh auditor dari tingkat madya, muda, pertama, penyelia, pelaksana lanjutan, dan pelaksana pada Badan Pengawasan Keuangan dan Pembangunan (BPKP) Perwakilan Provinsi Riau. Auditor yang bekerja pada BPKP Perwakilan Provinsi Riau berjumlah 98 orang. Jenis data yang digunakan dalam penelitian ini adalah data kuantitatif dan data kualitatif. Data kuantitatif adalah data yang diukur dalam suatu skala numerik (angka).Data kualitatif umumnya dikuantitatifkan agar dapat diproses lebih lanjut, caranya adalah dengan mengklasifikasikan dalam bentuk kategori (Kuncoro, 2013:146).

Data kuantitatif pada penelitian ini adalah data jumlah auditor yang bekerja pada BPKP Perwakilan Provinsi Riau yang bersumber dari http://www.bpkp.go.id/riau/. Sementara data kualitatif pada penelitian ini merupakan jawaban dari kuesioner yang diisi oleh responden. Sumber data yang digunakan dalam penelitian adalah data primer yaitu data yang diperoleh secara langsung dari responden atau sumber aslinya.

Untuk mendapatkan data yang diperlukan, peneliti menggunakan metode survey melalui penyebaran kuesioner. Metode survey 
merupakan metode pengumpulan data primer yang diperoleh secara langsung dari sumber asli (Sugiono, 2009).Seluruh kuesioner dibagikan kepada para responden di BPKP Perwakilan Provinsi Riau.

Metode analisis yang digunakan dalam penelitian ini adalah metode analisis kuantitatif yang merupakan analisis yang menggunakan angka dan perhitungan statistik untuk menganalisis hipotesis dan memerlukan beberapa alat analisis.

Alat analisis data dalam penelitian ini dilakukan dengan Structural Equation Modeling-Partial Least Square (SEM-PLS) dengan mengunakan software SmartPLS versi 3.2.3.Wold (1985) dalam Latan dan Ghozali (2012:6), Partial Least Square (PLS) merupakan metode analisis yang tidak didasarkan banyak asumsi, data tidak harus berdistribusi normal multivariate, tidak ada problem multikolinearitas antar variabel eksogen, sampel tidak harus besar.

Analisis statistik deskriptif dilakukan untuk memberikan gambaran atau deskripsi suatu data yang dilihat dari nilai rata-rata (mean), deviasi standar, maksimum, dan minimum.

Dalam penelitian ini analisis data statistik inferensial diukur dengan menggunakan software SmartPLS (Partial Least Square) yang telah dijelaskan sebelumnya. PLS mulai dari pengukuran model (outer model), struktur model (inner model) dan pengujian hipotesis.

Pengukuran model atau outer model mendefinisikan bagaimana setiap blok indikator berhubungan dengan variabel latennya. Model pengukuran (outer model) digunakan untuk menguji validitas konstruk dan reliabilitas instrument (Latan dan Ghozali, 2012). Dengan menggunakan SmartPLS ada tiga kriteria untuk melihat outer model yaitu Convergen Validity, Discriminant Validity, dan Composite Reliability.

Outer model dengan indikator reflktif di evaluasi melalui analisis faktor konfirmatory dengan menguji validitas konvergen (Convergen validity) dan validitas diskriminan (Discriminant Validity). (Campbell dan Fiske dalam Latan dan Ghozali 2012:78). Untuk penelitian tahap awal dari pengembangan skala pengukuran nilai loading 0,50 sampai 0,60 dianggap cukup (Latan dan Ghozali, 2012).

Reliabilitas menunjukkan konsistensi dan stabilitas dari suatu skor (skala pengukuran) (Kuncoro, 2013:175).Dalam PLS-SEM, untuk mengukur reabilitas suatu konstruk dilakukan dengan melihat nilai composite reability. Apabila nilai composite reability yang dihasilkan $\geq 0,70$ (comfirmatory research) maka semua konstruk dapat dikatakan reliabel.

Model Struktural atau Inner Model menggambarkan hubungan antar variabel laten berdasarkan pada teori substantif.Model struktural dievaluasi dengan menggunakan $R$ square untuk konstruk dependen.Pada pengujian hipotesis, untuk menguji hipotesis yang diajukan, dalam SEM PLS program Smart PLS 3.0 hasilnya dapat diketahui dengan menilai output tabel Path coefficient (mean, STDEV, Tvalues). Batas $\mathrm{T}$ statistik untuk menolak dan 
menerima hipotesis yang diajukan adalah 1,96 (t tabel signifikansi 5\%=1,96) (Latan dan Ghozali,2012).

Di dalam penelitian ini terdapat variabel intervening yaitu skeptisisme profesional auditor. Pengujian hipotesis mediasi dapat dilakukan dengan prosedur yang dikembangkan oleh Sobel dan dikenal dengan uji Sobel (Sobel test).

Pengaruh tidak langsung $\mathrm{X}$ ke $\mathrm{Y}$ melalui $\mathrm{M}$ dihitung dengan cara mengalikan jalur $\mathrm{X} \rightarrow \mathrm{M}$ (a) dengan jalur $\mathrm{M} \rightarrow \mathrm{Y}$ (b) atau ab. Jadi koefisien $a b=\left(c-c^{\prime}\right)$, dimana $c$ adalah pengaruh $\mathrm{X}$ terhadap $\mathrm{Y}$ tanpa mengontrol $\mathrm{M}$, sedangkan c' adalah koefisien pengaruh $\mathrm{X}$ terhadap Y setelah mengontrol M.

\section{HASIL DAN PEMBAHASAN}

Responden dalam penelitian ini adalah seluruh auditor di BPKP Perwakilan Provinsi Riau. Dari 98 kuesioner yang disebar, jumlah kuesioner yang kembali berjumlah 58 kuesioner $(59,18 \%)$ dan jumlah kuesioner yang tidak mendapat respon sebesar 40 kuesioner $(40,82 \%)$.

Analisis data dilakukan terhadap 58 jawaban responden yang memenuhi kriteria untuk dilakukan pengolahan data.

\begin{tabular}{|c|c|c|c|c|c|c|}
\hline & $\mathrm{N}$ & $\begin{array}{c}\text { Mini } \\
\text { mum }\end{array}$ & $\begin{array}{c}\text { Maxi } \\
\text { mum }\end{array}$ & Mean & Median & $\begin{array}{c}\text { Std. } \\
\text { Deviati } \\
\text { on }\end{array}$ \\
\hline RF & 58 & $\begin{array}{c}22.0 \\
0\end{array}$ & $\begin{array}{c}55.0 \\
0\end{array}$ & $\begin{array}{c}38.068 \\
966\end{array}$ & 38 & $\begin{array}{c}6.9707 \\
71\end{array}$ \\
\hline $\mathrm{P}$ & 58 & 3.00 & $\begin{array}{c}15.0 \\
0\end{array}$ & $\begin{array}{c}9.1379 \\
31\end{array}$ & 9,5 & $\begin{array}{c}3.7484 \\
42\end{array}$ \\
\hline $\mathrm{I}$ & 58 & $\begin{array}{c}19.0 \\
0\end{array}$ & $\begin{array}{c}35.0 \\
0\end{array}$ & $\begin{array}{c}28.965 \\
517\end{array}$ & 28 & $\begin{array}{c}2.9137 \\
64\end{array}$ \\
\hline $\mathrm{BK}$ & 58 & $\begin{array}{c}16.0 \\
0\end{array}$ & $\begin{array}{c}35.0 \\
0\end{array}$ & $\begin{array}{c}23.051 \\
724\end{array}$ & 23 & $\begin{array}{c}4.2485 \\
18\end{array}$ \\
\hline $\mathrm{SP}$ & 58 & $\begin{array}{c}45.0 \\
0\end{array}$ & $\begin{array}{c}67.0 \\
0\end{array}$ & $\begin{array}{c}53.775 \\
862\end{array}$ & 53 & $\begin{array}{c}4.3409 \\
24\end{array}$ \\
\hline $\mathrm{KA}$ & 58 & $\begin{array}{c}31.0 \\
0\end{array}$ & $\begin{array}{c}50.0 \\
0\end{array}$ & $\begin{array}{c}40.172 \\
414\end{array}$ & 40 & $\begin{array}{c}4.0268 \\
31\end{array}$ \\
\hline $\mathrm{MF}$ & & \multicolumn{7}{|c|}{} \\
\hline
\end{tabular}

Sumber: Data olahan, 2018

Suatu skala pengukuran disebut valid bila melakukan apa yang seharusnya dilakukan dan mengukur apa yang seharusnya diukur (Kuncoro, 2013: 172). Outer model dengan indikator refleksif di evaluasi melalui analisis faktor konfirmatory yang menggunakan pendekatan MTMM (MultiTrait-MultuMethod) dengan menguji validitas konvergen (Convergen validity) dan validitas diskriminan (Discriminant Validity).

Untuk penelitian tahap awal dari pengembangan skala pengukuran, nilai loading factor 0,5-0,6 masih dianggap cukup (Chin 1998 dalam Latan dan Ghozali, 2012:78). Loading faktor seluruh indikator pada penelitian memiliki nilai >0,5. Hal ini menjelaskan bahwa seluruh indikator yang ada pada konstruk telah memenuhi persyaratan validitas convergen.

Selain melihat dengan loading factor, untuk menguji validitas convergent dapat juga dengan melihat nilai AVE (Average Variance Extracted). Apabila nilai AVE yang dihasilkan semua konstruk lebih dari 0,50 maka konstruk memenuhi persyaratan validitas convergent (Latan dan Ghozali,2012).

\section{Tabel Nilai AVE}

\begin{tabular}{|l|l|}
\hline Konstruk Penelitian & AVE \\
\hline RF & 0,550 \\
\hline P & 0,931 \\
\hline SP & 0,505 \\
\hline KAMF & 0,590 \\
\hline
\end{tabular}

Sumber: Olahan Data SmartPLS 3.2.3 (2019)

Discriminant Validitity dari model pengukuran dengan reflektif indikator dinilai berdasarkan cross loading pengukuran dengan 
konstruk. Nilai loading factor untuk setiap indikator dari masing-masing variabel laten tidak ada yang memiliki nilai loading factor yang tidak paling besar dibanding nilai loading jika dihubungkan dengan variabel laten lainnya. Hal ini menjelaskan bahwa seluruh indikator yang ada pada dimensi konstruk setiap variabel memenuhi persyaratan validitas discriminant.

Reliabilitas menunjukkan konsistensi dan stabilitas dari suatu skor (skala pengkuran) (Kuncoro, 2013: 175). Untuk mengukur reliabilitas suatu konstruk dengan indikator refleksif dapat dilakukan dengan dua cara yaitu dengan melihat nilai cronbach's alpha dan composite reliability.

Tabel Nilai Cronbach's Alpha dan

\section{Composite Reliability}

\begin{tabular}{|l|l|l|}
\hline $\begin{array}{l}\text { Konstruk } \\
\text { Penelitian }\end{array}$ & $\begin{array}{l}\text { Cronbach's } \\
\text { Alpha }\end{array}$ & $\begin{array}{l}\text { Composite } \\
\text { Reliability }\end{array}$ \\
\hline RF & 0,919 & 0,930 \\
\hline P & 0,963 & 0,976 \\
\hline SP & 0,863 & 0,890 \\
\hline KAMF & 0,895 & 0,918 \\
\hline
\end{tabular}

Sumber : Data Olahan SmartPLS 3.2.3 (2018)

Pada tabel di atas dapat dilihat nilai Cronbach's Alpha dan Composite Reliability memiliki nilai di atas 0,70 . Hal ini berarti seluruh konstruk dalam penelitian ini terbukti reliabel.

Model Struktural atau inner model (kadang disebut juga Inner relation, structural model dan substantive theory) menggambarkan hubungan antar variabel laten berdasarkan pada substantive theory (Ghozali, 2014). Perubahan nilai $R$-Square dapat digunakan untuk menjelaskan pengaruh variabel laten eksogen tertentu terhadap variabel laten endogen apakah mempunyai pengaruh yang substantive. Hasil $R$ Square dengan menggunakan SmartPLS 3.2.3 dapat dilihat pada tabel dibawah ini.

Tabel Nilai $R$-Square

\begin{tabular}{|l|l|}
\hline & $\boldsymbol{R}$-Square \\
\hline KAMF & 0,471 \\
\hline SP & 0,374 \\
\hline
\end{tabular}

Sumber : Data Olahan SmartPLS 3.2.3

Berdasarkan tabel diatas, nilai $R$-square untuk variabel kemampuan auditor mendeteksi fraud adalah sebesar 0,471 , dan nilai $R$-square untuk variabel skeptisisme profesional sebesar 0374.

Uji T-Statistik dapat dilihat pada tabel path coefficient (Mean,STDEV, T-values). Apabila TStatistiknya $>1,96$ (level alpha 5\%), maka dapat dikatakan bahwa variabel eksogen berpengaruh signifikan terhadap variabel endogen (Latan dan Ghozali, 2012). Hasil pengujian dengan bootstrapping dari analisis PLS dapat dilihat pada gambar model struktural dan output result for inner weight

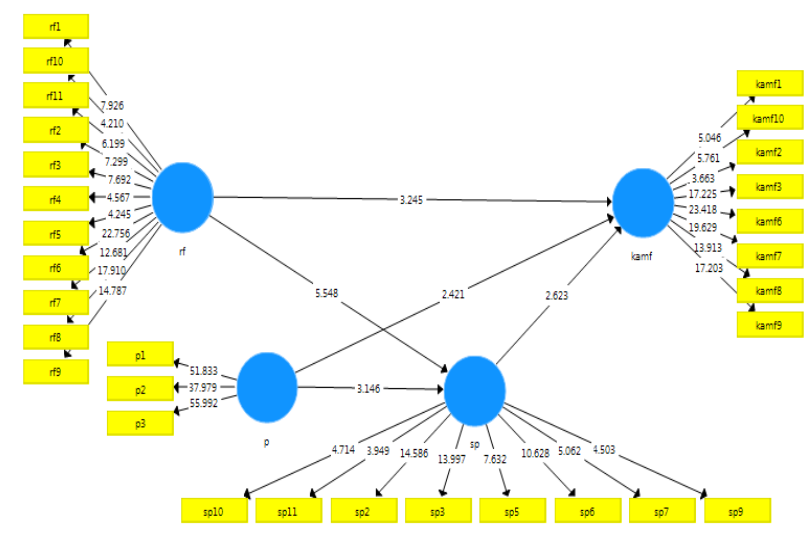

\section{Gambar Diagram Model Struktural}


Tabel Result for Inner Weights

\begin{tabular}{|l|c|l|l|l|l|}
\hline & $\begin{array}{c}\text { Origina } \\
\text { 1 } \\
\text { Sample } \\
(\mathrm{O})\end{array}$ & $\begin{array}{c}\text { Sample } \\
\text { Mean } \\
(\mathrm{M})\end{array}$ & $\begin{array}{c}\text { Standard } \\
\text { Deviation } \\
\text { (STDEV) }\end{array}$ & $\begin{array}{c}\text { Standard } \\
\text { Error } \\
(\text { STERR })\end{array}$ & $\begin{array}{c}\text { T } \\
\text { Statisti } \\
\text { cs } \\
(\mid \mathrm{O} / \mathrm{ST} \\
\text { ERR })\end{array}$ \\
\hline $\begin{array}{l}\text { SP -> } \\
\text { KAMF }\end{array}$ & 0,344 & 0,338 & 0,131 & 0,131 & 2,623 \\
\hline $\begin{array}{l}\text { RF -> } \\
\text { SP }\end{array}$ & 0,512 & 0,538 & 0,092 & 0,092 & 5,548 \\
\hline $\begin{array}{l}\text { RF -> } \\
\text { KAMF }\end{array}$ & 0,354 & 0,366 & 0,109 & 0,109 & 3,245 \\
\hline P -> SP & 0,319 & 0,315 & 0,101 & 0,101 & 3,146 \\
\hline $\begin{array}{l}\text { P -> } \\
\text { KAMF }\end{array}$ & 0,224 & 0,229 & 0,092 & 0,092 & 2,421 \\
\hline
\end{tabular}

Sumber: Pengolahan Data Dengan PLS (2019)

Pengujian hipotesis pengaruh tidak langsung diuji dengan menggunakan rumus sobel. Ringkasan perhitungan pengaruh tidak langsung dapat dilihat pada tabel di bawah ini :

\section{Tabel Pengaruh Tidak Langsung Ringkasan Perhitungan Uji Sobel}

\begin{tabular}{|l|l|l|l|l|l|l|l|}
\hline & $\mathrm{A}$ & $\mathrm{Sa}$ & $\mathrm{B}$ & $\mathrm{Sb}$ & $\mathrm{Ab}$ & $\mathrm{Sab}$ & $\mathrm{T}$ \\
\hline $\mathrm{RF}>$ & & & & & & 0,07 & 2,3 \\
$\mathrm{SP}>$ & 0,51 & 0,09 & 0,34 & 0,13 & 0,17 & 5136 & 44 \\
$\mathrm{KAMF}$ & 2 & 2 & 4 & 1 & 6128 & 5 & 11 \\
\hline $\mathrm{P}>\mathrm{SP}$ & & & & & & 0,05 & 1,9 \\
$>$ & 0,31 & 0,10 & 0,34 & 0,13 & 0,10 & 5933 & 61 \\
KAMF & 9 & 1 & 4 & 1 & 9736 & 2 & 91 \\
\hline
\end{tabular}

Sumber : Data Olahan SmartPLS 3.2.3 (2019)

\section{Pengaruh Red Flag terhadap}

\section{Kemampuan Auditor Mendeteksi Fraud}

Pada tabel diatas dapat diketahui bahwa hipotesis pertama didukung secara statistik yang dibuktikan dengan nilai $\mathrm{t}$ statistik signifikan pada level 5\% yaitu sebesar 3,245 $(>1,96)$. Hal ini membuktikan bahwa red flag berpengaruh signifikan terhadap kemampuan auditor mendeteksi fraud $\left(\mathrm{H}_{1}\right.$ diterima). Hasil penelitian ini sejalan dengan Moyes et al, (2006) mengenai efektifitas red flag terhadap kecurangan pelaporan pendeteksian keuangan.

Apabila auditor memiliki pemahaman maupun kesadaran akan tanda-tanda kecurangan, auditor dapat lebih cepat mengembangkan pencarian informasi ketika menemukan tanda-tanda kecurangan.

Pada tabel diatas dapat diketahui bahwa hipotesis kedua didukung secara statistik yang dibuktikan dengan nilai $\mathrm{t}$ statistik signifikan pada level 5\% yaitu sebesar 2,421 (>1,96). Hal ini membuktikan bahwa pelatihan berpengaruh signifikan terhadap kemampuan auditor mendeteksi fraud. Menurut Rahayu (2016), pelatihan audit kecurangan yang dilakukan akan semakin meningkatkan pengetahuan auditor mengenai audit kecurangan.

\section{Pengaruh Red Flag terhadap Skeptisisme Profesional}

Pada tabel diatas dapat diketahui bahwa hipotesis kelima didukung secara statistik yang dibuktikan dengan nilai $\mathrm{t}$ statistik signifikan pada level 5\% yaitu sebesar 5,548 $(>1,96)$. Hal ini membuktikan bahwa red flag berpengaruh signifikan terhadap skeptisisme professional. Menurut Moeller (2009:573), ketika terdapat sesuatu yang terlihat tidak benar, auditor internal harus selalu skeptis dan sadar akan sinyal peringatan tersebut. Ketika seorang auditor internal melihat satu bukti red flag atau lebih, auditor harus mencari informasi lebih dalam.

\section{Pengaruh Pelatihan terhadap Skeptisisme Profesional}

Pada tabel diatas hipotesis ke enam didukung secara statistik yang dibuktikan dengan nilai $\mathrm{t}$ statistik signifikan pada level 5\% yaitu sebesar 3,146 (>1,96). Hal ini membuktikan bahwa pelatihan berpengaruh signifikan terhadap skeptisisme profesional $\left(\mathrm{H}_{6}\right.$ diterima). Hasil penelitian ini sejalan dengan penelitian Fullerton 
dan Durstchi (2004) yang menunjukkan bahwa terdapat perbedaan sikap skeptisisme profesional pada auditor internal yang sudah mengikuti pelatihan. Pelatihan kecurangan efektif dalam mengubah kepribadian yang terlalu mempercayai lingkungan audit.

\section{Pengaruh Skeptisisme Profesional terhadap} Kemampuan Auditor Mendeteksi Fraud

Pada tabel diatas dapat diketahui bahwa hipotesis ke sembilan didukung secara statistik yang dibuktikan dengan nilai $\mathrm{t}$ statistik signifikan pada level 5\% yaitu sebesar 2,623 $(>1,96)$. Hal ini membuktikan bahwa skeptisisme profesional berpengaruh signifikan terhadap kemampuan auditor mendeteksi fraud.

Fullerton dan Durstchi (2004) menemukan bahwa untuk sebagian besar situasi, auditor internal dengan skeptisisme yang lebih tinggi akan mencari informasi yang lebih tajam daripada auditor dengan skeptisisme yang lebih rendah.

Pengaruh Red Flag terhadap Kemampuan Auditor Mendeteksi Fraud melalui Skeptisisme Profesional sebagai Variabel

\section{Intervening}

Pada tabel diatas hipotesis ke sepuluh didukung secara statistik yang dibuktikan dengan nilai t statistik signifikan pada level 5\% yaitu sebesar 2,34411 (>1,96). Hal ini membuktikan bahwa red flag berpengaruh signifikan terhadap kemampuan auditor mendeteksi fraud melalui skeptisisme professional.

Apabila auditor mengetahui adanya red flag, ia akan mengetahui letak risiko kecurangan dan cenderung curiga terhadap resiko kecurangan tersebut. Sikap skeptisisme yang terbentuk dari kepekaan akan red flag selanjutnya membuat auditor mengembangkan pencarian informasi sejak awal penugasan, sehingga membuat auditor lebih mudah mendeteksi kecurangan.

Pengaruh Pelatihan terhadap Kemampuan Auditor Mendeteksi Fraud melalui Skeptisisme Profesional sebagai variabel intervening

Pada tabel diatas hipotesis ke sebelas menunjukkan bahwa nilai $\mathrm{t}$ statistik signifikan pada level 5\% yaitu sebesar 1,96191 (>1,96). Hal ini membuktikan bahwa pelatihan berpengaruh signifikan terhadap kemampuan auditor mendeteksi fraud melalui skeptisisme professional.

Auditor yang sudah mengikuti pelatihan kecurangan akan memiliki keahlian maupun pengetahuan tambahan yang membuat auditor berpikir lebih kompleks dalam memeriksa kebenaran bukti audit, dan tidak mudah percaya akan bukti audit. Skeptisisme profesional yang terbentuk dari pelatihan selanjutnya akan meningkatkan kemampuan auditor mendeteksi kecurangan.

\section{PENUTUP}

\section{Kesimpulan}

Hasil uji path coefficient menunjukkan bahwa variabel red flag, pelatihan, dan skeptisisme profesional memiliki pengaruh signifikan terhadap kemampuan auditor mendeteksi fraud. Variabel red flag dan pelatihan memiliki pengaruh signifikan terhadap 
skeptisisme profesional. Variabel red flag dan pelatihan memiliki pengaruh signifikan terhadap kemampuan auditor mendeteksi fraud melalui skeptisisme profesional.

\section{Keterbatasan}

Penelitian ini hanya dilakukan di wilayah BPKP Perwakilan Provinsi Riau, sehingga sulit untuk mengungkapkan tindakan kecurangan secara menyeluruh yang ada di negara Indonesia.

\section{Saran}

Untuk peneliti selanjutnya diharapkan dapat mencakup wilayah yang lebih luas, tidak hanya wilayah Pemerintahan Provinsi Riau tetapi seluruh wilayah Sumatera. Bagi peneliti selanjutnya diharapkan dapat menambah variabel lain seperti audit tenure, internal audit effectiveness, maupun auditor responsibility dalam mengukur kemampuan auditor mendeteksi fraud baik melalui atau tidak melalui variabel intervening.

\section{DAFTAR PUSTAKA}

Arens, Alvin A., Randal J. Elder., Mark S. Beasley. 2008. Auditing dan Jasa Assurance. Edisi Keduabelas. Erlangga. Jilid 1. Jakarta

Cressey, D. R. 1953. Other People's Money. Montclair, NJ: Patterson Smith, pp.1-300.

DiNapoli, Thomas P. 2008. Red Flags for Fraud. State of New YorkOffice of the State Comptroller.Diakses tanggal 26
Maret 2018.

Drogalas, George., Michail Pazarskisb, Evgenia Anagnostopouloua, and Angeliki Papachristoub. 2017. The effect of internal audit effectiveness, auditor responsibility and training in fraud detection. Accounting and Management Information Systems Vol. 16, No. 4, pp. 434-454. University of Macedonia, Greece. T.E.I. of Central Macedonia, Greece.

Fullerton, Rosemary R., and Durtschi, Cindy. 2004. The Effect of Professional Skepticism on The Fraud Detection Skills of Internal Auditors. Working Paper Series. Utah State University School of Accountancy

Indonesia Corruption Watch. 2017. Tren Penindakan Kasus Korupsi Tahun 2017. Jakarta.

Latan,H., dan Imam Ghozali. 2012. Partial Least Square : Konsep, Teknik dan Aplikasi SmartPLS 2.0 M3. Semarang: Badan Penerbit Universitas Diponegoro.

Marks, Jonathan, 2012. The Mind Behind The Fraudsters Crime: Key Behavioral And Environmental Elements. Crowe Howarth LLP (Presentation).

Moeller, Robert R., 2009. Brink's Modern Internal Auditing. A Common Body of Knowledge. Seventh Edition. John Wiley \& Sons, Inc., Hoboken, New Jersey.

Moyes, Glen D., Ping Lin., Raymond M. Landry, Jr., Handan Vicdan. 2006. Internal Auditors' Perceptions of tlkshe Effectiveness of Red Flags to Detect 
Fraudulent Financial Reporting. The University of Texas-Pan America.

California State University-Long Beach. Journal of Accounting, Ethics \& Public Policy.Volume 6,No.1.

Nasution, Hafifah., dan Fitriany. 2012.

Pengaruh beban kerja, pengalaman audit dan tipe kepribadian terhadap skeptisme profesional dan kemampuan auditor dalam mendeteksi kecurangan.Universitas Islam Negeri Syarif Hidayatullah Jakarta., Universitas Indonesia

Pramana, Andy Chandra., Gugus Irianto.,

Nurkholis. 2016. The Influence Of Professional Skepticism, Experience And Auditors Independence On The Ability To Detect Fraud. Imperial Journal of Interdisciplinary Research (IJIR). Vol-2, Issue-11， 2016 ISSN: 2454-1362. Accounting, Economic \& Business Faculty, Brawijaya University.

Putri, Kompiang Martina Dinata. 2017. Pengaruh Fraud Audit Training, Skeptisisme Profesional Auditor dan Audit Tenure Pada Kemampuan Pendeteksian Kecurangan. Tesis. Program Pasca Sarjana Fakultas

Ekonomi Dan Bisnis Universitas Udayana. Denpasar.

Rahayu, Siti., dan Gudono. 2016. Faktor-Faktor yang mempengaruhi Kemampuan Auditor dalam Pendeteksian Kecurangan: Sebuah Riset Campuran dengan Pendekatan Sekuensial Eksplanatif.
Simpusium Nasional Akuntansi, XIX, Lampung.

Singleton, Tommie W., Aaron J. Singleton. 2010. Fraud Auditing and Forensic Accounting. Fourth Edition. John Wiley \& Sons, Inc., Hoboken, New Jersey. 